\title{
SOPHIA
}

PEER REVIEW JOURNAL

CROSSING BORDERS, SHIFTING BOUNDARIES - IMAGE, BODY AND TERRITORY

ISSN: 2183-8976 [PRINT] 2183-9468 [ONLINE]

Volume 3, Issue 1 | Publication year: 2018

DOI 10.24840/2183-8976_2018-0003_0001_03

(C) SCOPIO EDITIONS

HOMEPAGE: HTTPS://WWW.SOPHIAJOURNAL.NET

\section{A VERNACULAR OF GENERIC GROWTH}

\author{
Kalen McNamara
}

\section{Abstract}

Studying a series of photographs taken by Gavin Brown in Houston, Texas, I argue that Brown sets up a provocative feedback loop between content and composition that offers a new way of seeing our generic built environment. In his images of fragments of cars, strip-mall ceilings, and new constructions, Brown uses various techniques to separate the object from its context and meaning, isolating one of the city's foundational tenets to show us a vernacular of economic growth itself. While a vernacular is typically tied to a place, this vernacular is tied to a state of mind.

Keywors: Gavin Brown, Texas, Photography, Consumer Culture, Vernacular Architecture 


\section{A VERNACULAR OF GENERIC GROWTH}

Written by Kalen McNamara

\section{Specifying the generic}

I once heard Houston, Texas described as "the America of America." I believe it is neither the city's racial diversity nor its socioeconomic segregation that make it quintessentially American, but the way the city embodies a generic ideal of growth. Thanks to the presence of energy and healthcare industries, Houston consistently reaches the top ranks of US cities in terms of job availability and affordability. Despite its generic promise, Houston is a peculiar place, muddy and lush, host to a constant fluvial battle between concrete and bayous, a sprawling de-centered metropolis beset with traffic jams on heroic highway overpasses that can make your heart ache against your better judgment. In a series of photographs of the city by Gavin Brown titled Our space is a mess, we don't see that version of Houston, but instead the logic that sets it in motion and propels it forward; Brown isolates one of the city's foundational tenets to show us a vernacular of generic growth.

A vernacular architecture of a given place encompasses the smaller details and broader proportional relationships of the built environment in a way that creates coherence across different scales, all coalescing into a particular attitude toward space, form, and materiality. Because the term "vernacular" implies specificity and thus variance from, even defiance toward, a generic condition, a vernacular of generic growth would seem to be an oxymoron. In this series, however, Brown uses photography to highlight the specific qualities of the generic built environment, and to elucidate the worldview that drives its construction and propagation. While a vernacular architecture is typically based in a particular place, this series of photographs produces a vernacular of a state of mind.

The boom-and-bust tendency of Houston's oil and gas industry, coupled with a certain Texan hostility to regulation, enables heedless expansion and speculative development that results in a highly generic and poorly-constructed built environment. is condition, now found in cities all over the world, is familiar to most of us, but due precisely to its ubiquity we have become desensitized to it. This habituation creates a sense of growth's inevitability, which Brown undermines through a photographic technique that creates a slippage between reality and our mental catalog of the built environment. In his images of fragments of cars, strip-mall ceilings, and new construction, he invents several techniques to separate the object from its context and meaning, depicting the objects not as artifacts of human culture but instead as the fodder of blind economic proliferation. The series amounts to a vernacular study of the generic built environment, and an important reminder that the generic is far from neutral. 

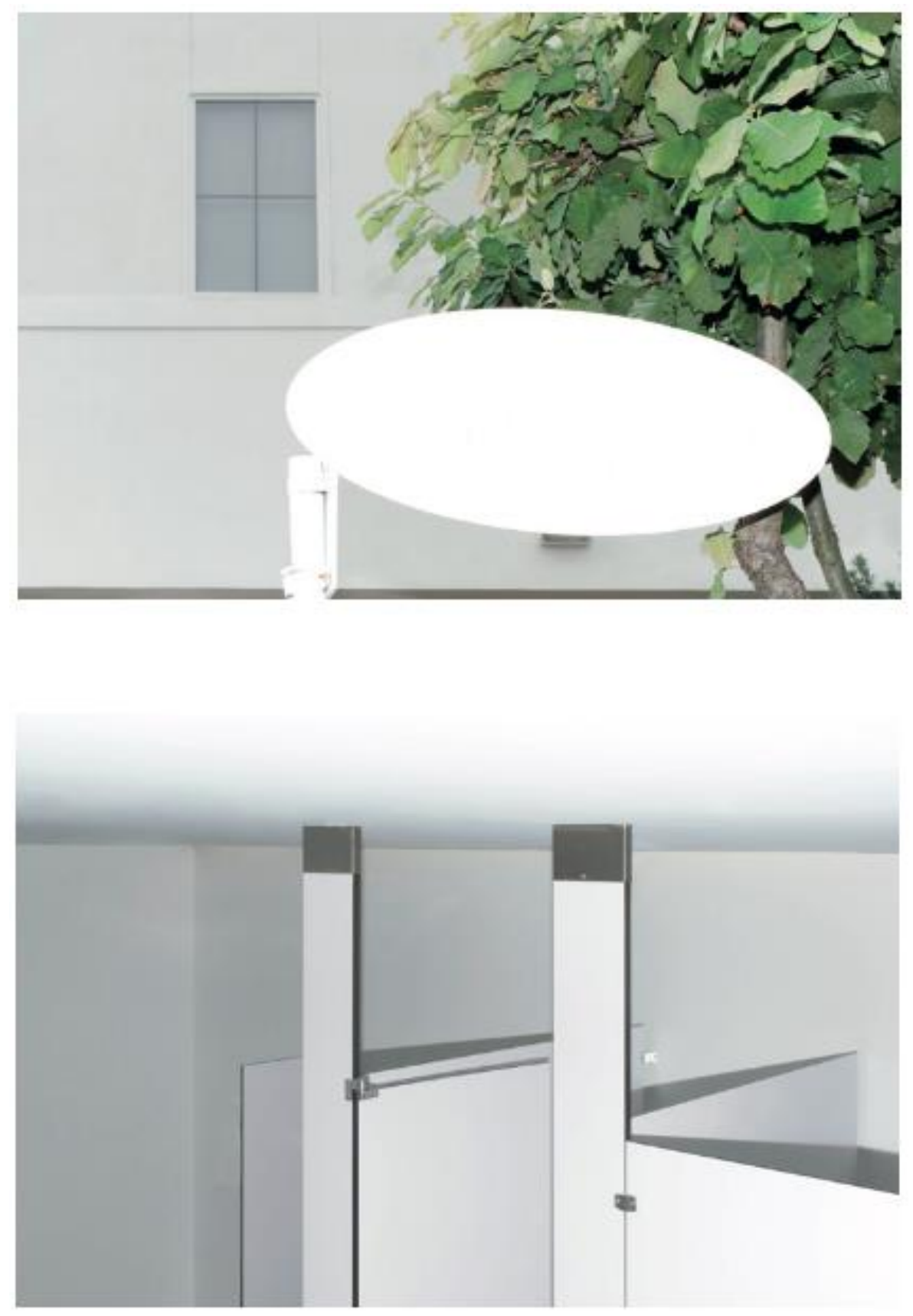

\section{GAVIN BROWN}

Synthetic Stucco and Plywood Sign in Alkyd Polymer Paint,

from the series "Our Space is a Mess", 2017

Houston, Texas; Digital Photograph

\section{GAVIN BROWN}

Bathroom Partitions in Phenolic and Melamine Resin laminate,

from the series "Our Space is a Mess", 2017

Houston, Texas; Digital Photograph

\section{Slightly unfamiliar}

Brown triggers this change in our way of seeing by means of several, often overlapping techniques. Through atypical vantage points, strategic cropping, and deliberate overexposure, the series forges a new link between content and composition, setting up a provocative feedback 
loop between the surfaces of the generic objects captured by the camera and the twodimensional plane of the photograph itself. In many of the photographs in the series, the synthetic materials that constitute our built environment, from the scale of furniture to that of infrastructure, are flattened and overexposed. The standard objects and spaces being photographed hover just at the edge of recognition, their surfaces transformed into purely compositional elements. The photographs undermine the ordinariness of the depicted objects, provoking in us a sense of alienation from the fruits of our own production, and a heightened sensitivity to the truly bizarre aspects of our material culture.

One photograph of the series shows a TV satellite dish against one of Houston's countless speculatively-built townhomes, with the normally concave dish rendered as a zone of flat white. Overexposure causes the perfect white ellipse of the flattened parabolic dish to fall out of the image completely, creating a subtle sense of estrangement in an otherwise banal scene. The collection of objects in the scene is familiar enough, but the unusual vantage point, the zoom and crop, and especially the overexposure, which casts a synthetic pall over even organic matter, combine to produce a way of seeing that is a step removed from human vision.

Given the series' focus on overlooked aspects of the built environment, as well as the absence of people in the photographs, this work has some resonances with the New Topographics movement of the 1970s. But while the work of photographers such as Lewis Baltz often showed an entire building or facade in a relatively objective way, Brown's use of cropping limits the viewer's comprehension and charges these photographs with subjectivity. Within Brown's series, the horizontal photographs are most aligned with New Topographics, in that an elevated vantage point creates a disembodied view and a sense of flatness. In one photograph of a construction site, the repetition and horizontal banding of construction materials accentuates this flattening effect. Another photograph in this series shows the facade of a distribution center, a building clearly designed for throughput rather than people. Yet the composition is centered on an arrangement of white and gray cladding panels that seem to form the proscenium of a stage, echoing the deadpan attitude seen in many of Ed Ruscha's 1960s photographs of the American roadside landscape. is ironic detachment and use of a panoramic view to flatten the image and overwhelm the viewer's sense of scale are also familiar from the more contemporary work of Andreas Gursky, whose photographs often show the stupefying extent of mass production on a global scale. 

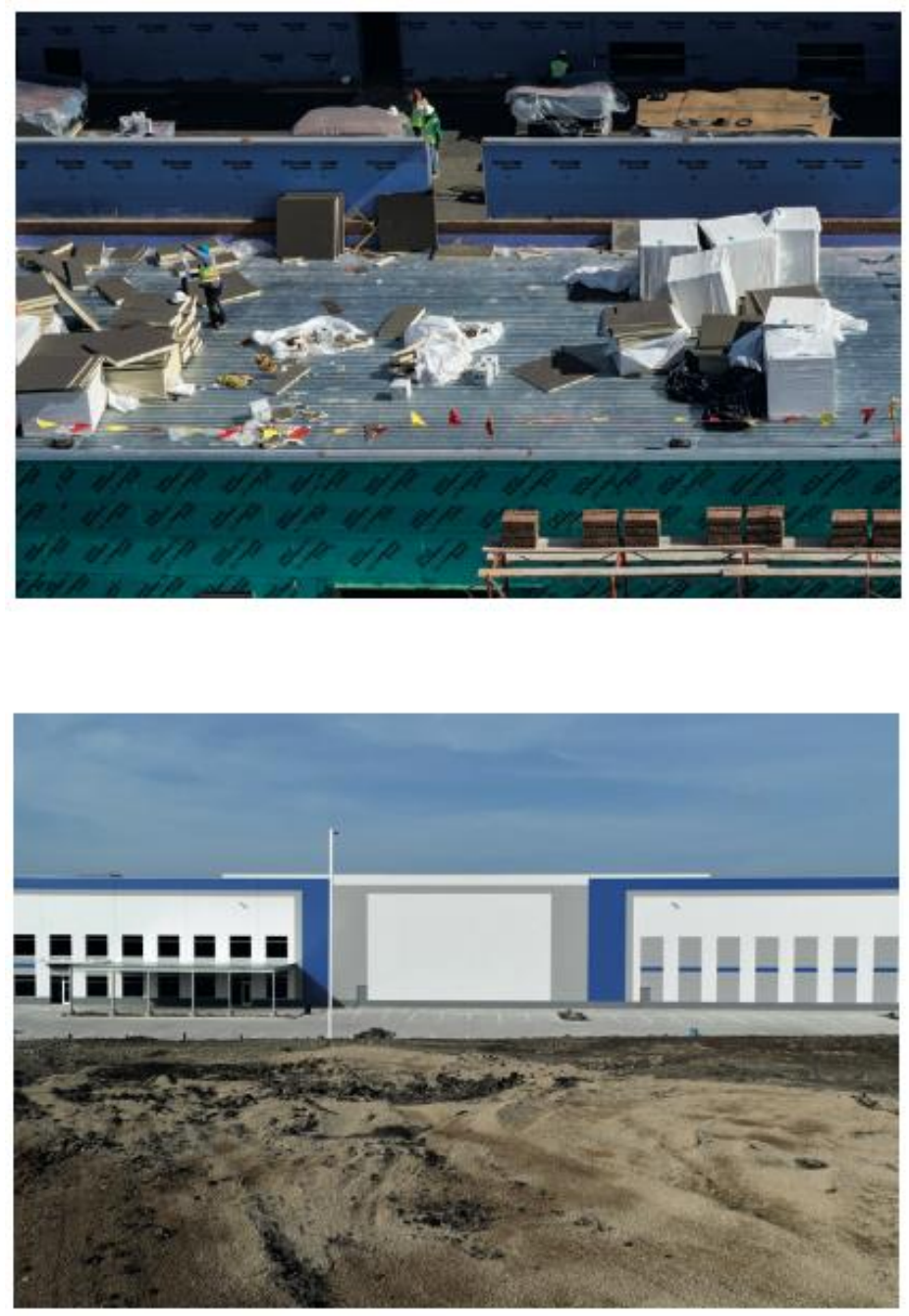

GAVIN BROWN

Gymnasium Roof with Layered Vapor Barrier, Brick, Foam Extrusions, Steel Decking, Gypsum Board, and Asphalt Paper, from the series "Our Space is a Mess", 2017 Houston, Texas; Digital Photograph

GAVIN BROWN

Distribution Center with Synthetic Stucco over Extruded Polystyrene, from the series "Our Space is a Mess", 2017

Houston, Texas; Digital Photograph

Images such as Gursky's famous "Amazon" (2016) overwhelm and dwarf the viewer, showing the spoils of a system so bafflingly large and complex, it seems it can't possibly have been engineered by humans. In Gursky's enormous landscapes, both interior and exterior, relentless repetition begets abstraction, transforming a multitude of individual entities into a singular, continuous pattern. Brown's photos also disrupt our sense of scale, but in a different way. Within the series, the horizontally-oriented photographs reference influences such as Baltz, Ruscha, and Gursky more directly, while the vertically-oriented photographs combine and expand upon those influences to create something different. Abstraction and alienation come not from repetition, but from finite sets of familiar objects. We see things we normally relate to with our bodies in prescribed ways, but the images are constructed in a manner that disrupts those relationships. 
Overexposure of these images endows them with a willful flatness that undermines attempts to read them as representations of three-dimensional space. In that way, they are related to photograms, in which photosensitive paper registers the trace of an object directly, unmediated by a camera. In early 20th-century experiments with this medium, artists such as Man Ray and László Moholy-Nagy made photograms using generic household objects, collapsing the threedimensional object into a flat compositional plane. This camera-less photography contained a provocative paradox; on one hand the direct contact between the depicted object and the photosensitive film made the photogram a faithful index of reality; on the other hand, however, the resulting image often transformed the object beyond recognition. is same tension regarding the documentary role of the photographic image exists in Brown's series, which also relies upon objects common enough to be recognizable from a silhouette or unfamiliar angle, creating a scaleless realm for objects to exist just beyond human vision and categorization. But if the photograms of Ray and Moholy-Nagy used generic objects as a medium through which to experiment with composition and affect, Brown's photographs are more deliberate in their use of standard objects and spaces. These images operate politically to challenge the generic as a condition, one that is so widespread that it can be difficult to capture.

This effect is particularly evident in the two photographs of cars. The images are tightly cropped to show not archetypal vehicles but assemblies of smooth and reflective surfaces. Imaged in this way, the cars lose any scalar relationship to the human body, figuring instead as scaleless compositions comprised of familiar materials and parts which nonetheless fail to coalesce into the object we expect. The photographs of cars also play an important role in the series in the context of broader discourse about urban sprawl. Houston is a city typically experienced from the inside of a car, a condition of viewing the landscape from a place of local intimacy yet at a complete remove. 

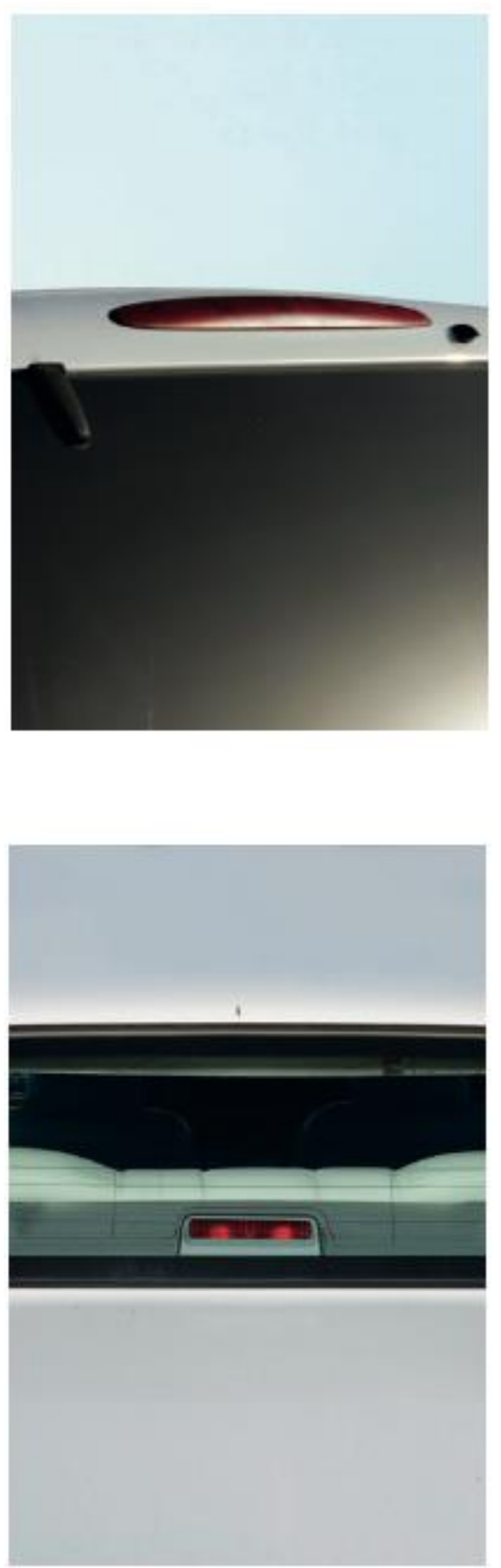

GAVIN BROWN

SUV, from the series"Our Space is a Mess", 2017

Houston, Texas; Digital Photograph

\section{GAVIN BROWN}

Car with: Scratch rough Clear Coat, Base Coat, and Primer to Steel Sheeting;

Windhshield with Wires Laminated between Green Tinted Safety Glass; Black Vinyl Boarder and Synthetic Rubber Gasket; Interior in Various Plastics and Leather, from the series "Our Space is a Mess", 2017

Houston, Texas; Digital Photograph 
The car photographs capture a fraught relationship between interior and exterior, an attitude in which outside space is seen as a territory to be managed through the same protocols that organize the climate-controlled interior. In another photograph in the series that shows a distribution center, the huge expanse of excavated soil in the foreground is muted by the bland EIFS warehouse façade beyond, appearing less like a disturbed natural landscape and more like a carpet that carries the spreadsheet logics of the warehouse interior beyond the building itself. In many ways cars are the perfect victim of Brown's particular vision: they embody this fraught division between interior and exterior space; they sell themselves by their distinctive volumetric form (all the better to be flattened); and lastly, as economic products they are vectors of generic growth. Cars are a locus of a fixation on newness in American culture, and what is excessive growth if not newness without progress?

\section{Blank space, synthetic surfaces}

Brown's feedback effect between the surfaces of the depicted objects and the compositional plane of the photograph is highly dependent upon the material qualities of the generic landscape. While the use of cropping and vantage point speak to an emotional intelligence that understands how a viewer will interpret the photograph, the other crucial ingredient of this effect is a technical intuition that anticipates how the materials of the photographed object will be rendered and transformed by the camera. For example, the white synthetic surfaces that make up so much of the generic built environment are overexposed and flattened in the photographs, creating even fields of knockout white. These flat zones push the status of the image farther away from a documentation of real space and depth, and closer to a twodimensional composition into which reality is collapsed. And yet the image remains both twodimensional and three-dimensional at the same time, frustrating our understanding of what a photograph does. In one image of a building's entry vestibule, the white of the opening door seems to reach beyond the plane of the page to divide the matter of the photograph itself. The argument for the photograph as a depiction of three-dimensional depth is undermined, and the argument for the photograph as two-dimensional compositional matter is literally cut in half by the real presence of the open door.

That this interplay is dependent upon exposure means that the color white has an important presence across the series. Lewis Baltz observed that in color photographs, "black implies substance and location", while in black-and-white photographs it implies a void ${ }^{1}$. The corollary to Baltz' statement is that in black-and-white photographs white implies material presence, while in color photographs, as in reality, white implies a default condition, an unassigned value.

\footnotetext{
1 Lewis Baltz. 1984. Konsumerterror-Industrial Alienation. Aperture (96). 6.
} 


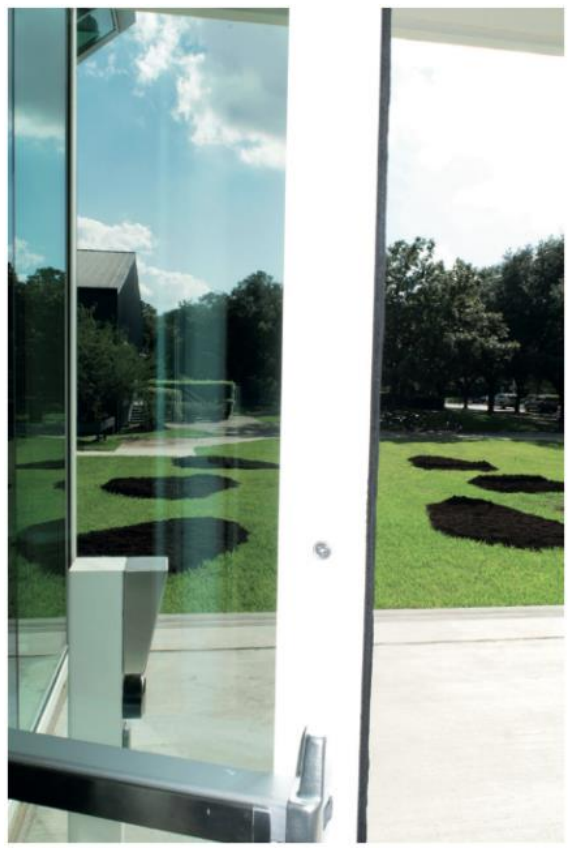

GAVIN BROWN

Pigmented, Insulated Glass Laminated with Polyvinyl Butyral,

from the series "Our Space is a Mess", 2017

Houston, Texas; Digital Photograph

In Brown's photographs of the white matter of the generic built environment, overexposure literally brings this blank, default quality to the surface. In his series Blank (2010-present), the photographer Andreas Gefeller also depicts generic infrastructure through the filter of overexposure. In his work, nondescript office buildings and highway overpasses are blanched nearly beyond recognition. Described as "documentary photography to create the effect of an artificial world ${ }^{2}$, Gefeller's Blank series takes overexposure to the point of stylization. While Brown's and Gefeller's series share subject matter and, to an extent, a technique, the radioactive electricity of Gefeller's photographs finds a foil in the inertness of Brown's images, which show no registration of movement or time. Even if the evidence of decay in Gefeller's photographs is obliterated by light, the resulting image itself seems to reference decay, like an aged and sunbleached Polaroid.

By contrast, the photos in Brown's series show no signs of decay, feature no event, and do not register time at all.

\section{Background in focus}

This lack of temporal registration is integral to Brown's series; the cheaply-built and newly constructed objects and buildings on which he trains his camera have material qualitiessmoothness, regularity, lack of decay or patina-that are ideal for his interplay between content and composition. Almost entirely devoid of human presence, the images lack action - or rather the actors are objects rather than people. Composed in a way that charges typically unimportant visual matter with a sense of immediacy and drama, the photographs make us feel displaced

2 Burris, Jennifer.2011. The "Urban Photogénie" of "Architainment". The Journal of Aesthetics and Art Criticism (Vol. 69, No. 1). 101. 
from our temporal moment, seeming to depict images of a world without us. In the only photograph that shows people, workers are staging a construction site, unpacking and readying building materials. There is something almost comic in the way the few people in the scene are outnumbered by the stacks of material, the entire image crossed by a banner of safety flags flapping triumphantly in the wind. This photograph offers a light-hearted nod to a more serious theme running through the series. The generic objects and spaces that we consider background noise continue to multiply unabated, occupying more and more of our mental and physical space. Habituated to this landscape, and numbly convinced of the inevitability of economic expansion, we gain a new way of seeing through Brown's series.

There is no doubt a political dimension in the works of Baltz, Ruscha, Gursky, and Gefeller, all of whom have an interest in overlooked aspects of our built environment. The New Topographics movement and the Dusseldorf School share a desire to image the world in an objective way through photography, often working in a panoramic mode.
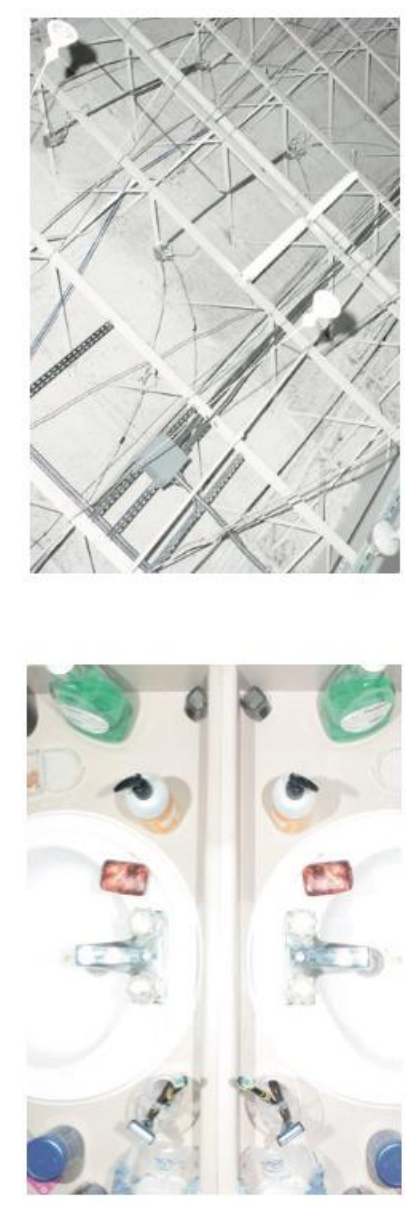

GAVIN BROWN

I Gallery Ceiling with Spray Fire Retardant, Variously Finished Steel Lace, And Plastic-Coated Wiring,

from the series "Our Space is a Mess", 2017

Houston, Texas; Digital Photograph

GAVIN BROWN

Cosmetics on Laminate Counter Top,from the series "Our Space is a Mess", 2017

Houston, Texas; Digital Photograph 
But panoramic views run the risk of romanticizing their subjects; the political message is dissolved in the hedonistic thrill of the all-seeing view. Brown posits an alternative with this series: a snapshot mode, which charges images with an accidental quality, as if they had been taken by a drone flying just above head height, with six degrees of freedom of movement. His method is a different answer to the search for objectivity, one which exploits the inherent naivety of the camera. The resulting images-disembodied, decontextualized, flattened-give us a way to see our world not on our terms, but through the camera's eye. Brown takes inventory of our generic built environment and uses this method to undermine its ordinariness, creating a vernacular of generic growth.

"Vernacular" carries another important connotation. Not only does the word imply a specific exception to the general rule, it also suggests a mode that lies outside the purview of culture. In ancient Rome, for example, Classical Latin was a standardized language used in literature and legal matters, while Vulgar or Vernacular Latin was used only outside the sphere of high culture. By now we are familiar with artistic pursuits which attempt to elevate low culture into the realm of high culture, but Brown's vernacular of our generic environment turns this format on its head. The spaces depicted in the series seem to be an afterthought, a default condition, making no claim to cultural relevance. Only through Brown's complex interplay between the surfaces of the depicted objects and the plane of the photograph itself are we able to see that these spaces, propagating rapidly with economic expansion, increasingly constitute our culture more than we may like to admit.

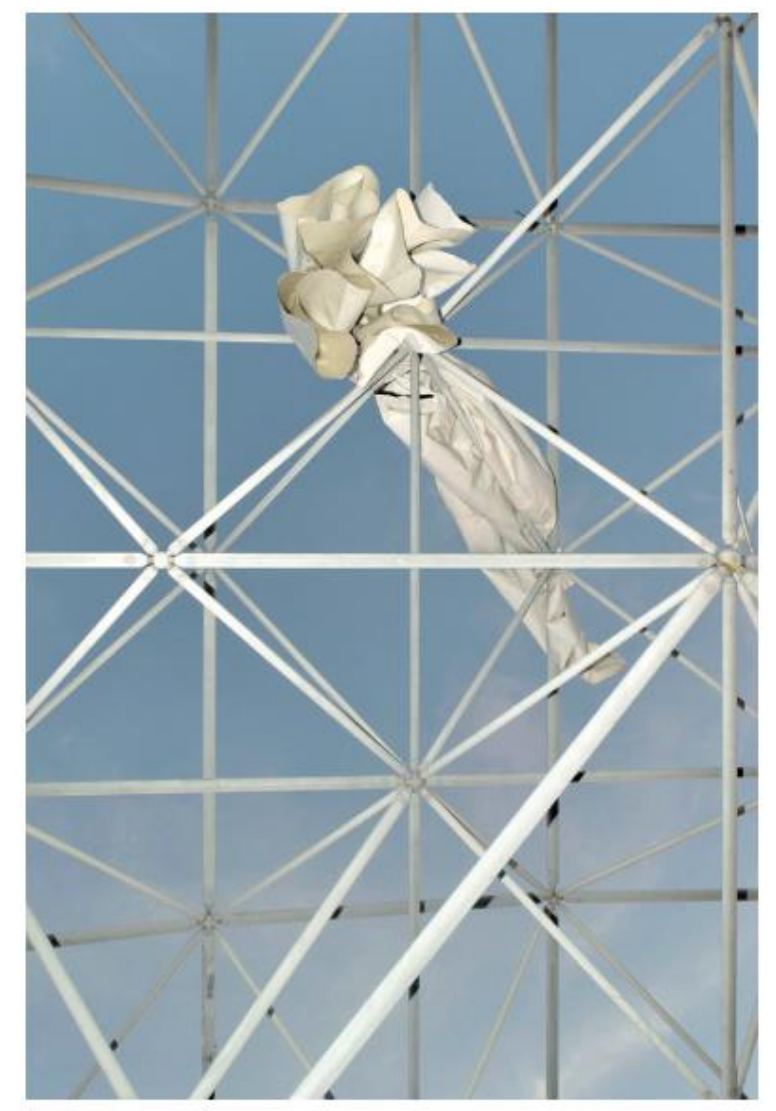




\section{Bibliography}

Baltz, Lewis.1984. Konsumerterror: Late-Industrial Alienation. Aperture (96).

Burris, Jennifer. 2011. The "Urban Photogénie" of "Architainment". The Journal of Aesthetics and Art Criticism (Vol. 69, No. 1). Krumwiede, Keith. 2002. SuperModelTM Homes. Cite (54).

Lerup, Lars. 2011. One Million Acres \& No Zoning. Architectural Association.

Walgate, M. 2018. http://www.andreasgefeller.com/blank/text 